\title{
EFEITO DA VENTILAÇÃO NATURAL E MECÂNICA SOBRE O DESEMPENHO DE PORCAS EM LACTAÇÃO'1
}

\author{
CARLOS CLÁUDIO PERDOMO², LUÍS CARLOS DE OLIVEIRA FERNANDES³, \\ ANTÔNIO LOURENÇO GUIDONI ${ }^{2}$ e FLAVIO BELLO FIALHO
}

\begin{abstract}
RESUMO - O controle efetivo da ventilação é fundamental para maximizar o bem-estar, o desempenho e a saúde dos suínos. Este trabalho avaliou o efeito de sistemas de ventilação natural através de janelas basculantes (com e sem exaustor eólico) e mecânica, dimensionados para a retirada da carga térmica incidente, nas condições de verão, sobre o condicionamento ambiental e desempenho de porcas em lactação, em Concórdia, SC, no período de 1991/92. Embora tenha sido observado efeito da estação do ano $(\mathrm{P}<0,05)$ sobre as variáveis ambientais, não houve alterações significativas na resposta animal $(\mathrm{P}>0,05)$. O condicionamento térmico no verão foi considerado estressante em todos os sistemas, com temperaturas (Ti) elevadas $\left(>22,0^{\circ} \mathrm{C}\right)$, taxas de ventilação (Vi) deficientes $(<0,2 \mathrm{~m} / \mathrm{s})$, baixo consumo alimentar (CR) $(<4,3 \mathrm{~kg} / \mathrm{dia})$ e alto intervalo desmama-cio (IDC) ( $>13$ dias), em comparação com as observadas no inverno: Ti $\left(<19,0^{\circ} \mathrm{C}\right)$, Vi $(<0,1 \mathrm{~m} / \mathrm{s}), \mathrm{CR}(<4,57 \mathrm{~kg} / \mathrm{dia})$ e IDC ( $<7$ dias), respectivamente. Concluiu-se que sistemas de ventilação dimensionados apenas para a retirada da carga térmica incidente (radiação solar, calor animal e fontes internas de aquecimento) são viáveis para o inverno, mas resultam em desconforto térmico no verão, em face da maior exigência de ventilação.
\end{abstract}

Termos para indexação: conforto térmico, maternidade, sistemas de ventilação, tipos de fechamento.

EFFECT OF NATURAL AND MECHANICAL VENTILATION ON PERFORMANCE OF LACTATION SOWS

\begin{abstract}
Air movement has been shown to influence performance of confined swine, and that appropriate air flow is fundamental to better animal comfort, and to minimize sanitary problems. The effect of window with and without aeolic exhaustion and mechanical ventilation designed only for hot season was evaluated at Concordia, SC, Brazil, during 1991/92. Although effect of season $(\mathrm{P}<0.05)$ had been observed on environment that was not the case on animal performance $(\mathrm{P}>0.05)$. The hot season environment was stressing for animals, due to higher environment temperature $(\mathrm{Ti})\left(>22.0^{\circ} \mathrm{C}\right)$, low air velocity $(\mathrm{Vi})(<0.2 \mathrm{~m} / \mathrm{s})$, reduced feed intake $(\mathrm{CR})(<4.3 \mathrm{~kg} /$ day), as well as increased weaning estrus interval (IDC) ( $>13$ days) during the hot season as compared to cold season: Ti $\left(<19.0^{\circ} \mathrm{C}\right)$, $\mathrm{Vi}(<0.1 \mathrm{~m} / \mathrm{s}), \mathrm{CR}(<4.57 \mathrm{~kg} /$ day $)$ and IDC ( $<7$ days $)$, respectively. In conclusion, ventilation systems based only on natural openings are sufficient for cold season, but are not for hot season due to increase in the ventilation needs.
\end{abstract}

Index terms: thermal comfort, farrowing housing, opening forms.

\footnotetext{
${ }^{1}$ Aceito para publicação em 9 de junho de 1998.

Extraído da Tese de Doutorado do primeiro autor, UFRGS.

${ }^{2}$ Eng. Agr., D.Sc., Embrapa-Centro Nacional de Pesquisa de Suínos e Aves (CNPSA), BR 153 km 110, Caixa Postal 21, CEP 89700-000 Concórdia, SC. E-mail: perdomo@cnpsa.embrapa.br

${ }^{3}$ Eng. Agr., Ph.D., Dep. de Zootecnia, UFRGS, Avenida Bento Gonçalves 7712, Caixa Postal 776, CEP 91540-000 Porto Alegre, RS.

${ }^{4}$ Eng. Agr., Ph.D., Embrapa-CNPSA.
}

\section{INTRODUÇÃO}

A importância da ventilação resulta da intensidade com que afeta as perdas de calor por condução, dissipando o calor de radiação e convecção, elevando a temperatura crítica do animal e conduzindo-o a um maior gasto energético (Morrison \& Mount, 1971; Le Dividich \& Rinaldo, 1989). Em 
regiões cuja temperatura se mantém sempre acima da requerida para o conforto, deve prevalecer a ventilação baseada na razão térmica (Rivero, 1986). Se o objetivo básico da ventilação é a redução do calor sensível, o limite de conforto a ser alcançado passa a ser o do próprio ar usado para ventilar.

O primeiro critério para o dimensionamento de um sistema de ventilação na produção de suínos, deve basear-se nos requisitos básicos de exigência animal, no suprimento de oxigênio e na redução máxima do $\mathrm{CO}_{2}$, e o segundo, na melhoria das condições higrotérmicas da edificação, mediante redução ou incremento das trocas de calor por convecção e evaporação entre os indivíduos e o ar ambiente. Conhecida a carga térmica incidente sobre a edificação, calcula-se a vazão de ar necessária para reduzi-la a um valor aceitável (Mascaró, 1986; Nääs, 1989).

A velocidade e a distribuição do fluxo de ar são afetadas pelo tamanho e tipologia das aberturas (Souloumiac \& Itier, 1989), mas a variação na superfície de admissão do ar pode melhorar os circuitos internos da temperatura. Os fechamentos basculantes com elementos pivotantes horizontais móveis, geometricamente centralizados e dispostos de forma a dirigir o ar para os animais, parecem ser uma opção adequada para o controle e melhoria dos sistemas de ventilação. Mas, qualquer que seja a vazão, o ar incidente sobre os animais deve ter uma temperatura homogênea. Para a consecução deste objetivo, há necessidade de regular as aberturas de admissão de ar de acordo com a diferença de temperatura entre o meio externo e interno (Granier et al., 1989).

Objetivou-se no presente trabalho, avaliar o efeito dos tipos de fechamento e da ventilação mecânica em sistemas de ventilação dimensionados para a retirada da carga térmica incidente no verão (radiação solar, calor animal e fontes internas de aquecimento) sobre o condicionamento ambiental da maternidade e desempenho de porcas em lactação durante a época quente e fria.

\section{MATERIAL E MÉTODOS}

O experimento foi conduzido na maternidade do Sistema de Produção de Suínos da Embrapa-Centro
Nacional de Pesquisa de Suínos e Aves (CNPSA), em Concórdia, SC, no período de dezembro de 1991 a setembro de 1992. Utilizaram-se três salas $(8,3 \times 4,2 \times 2,5 \mathrm{~m})$ de uma edificação compacta, com corredor de acesso na fachada norte, coberta com telha de barro "francesa", com forro de emaclite gessado, piso parcialmente ripado, sistema de fossa com retenção de liquame e drenagem do excesso, com cinco celas de parideiras, dispostas linearmente em cada sala (Fig. 1).

Foram avaliados três tratamentos, num delineamento inteiramente casualizado, sendo dois sistemas de ventilação natural através de janelas, com (SVCE) e sem exaustor eólico (SVSE), e um mecânico por "insuflamento e exaustão" (VMEC), com 20 repetições no verão e 15 no inverno, tendo-se a porca com 9 leitões como unidade experimental. Utilizaram-se os tipos de fechamento basculante com três elementos horizontais móveis $(2,8 \mathrm{x}$ $1 \mathrm{~m}$ ) para os sistemas naturais, e o mecânico, controlado por termostato (acionado a temperaturas superiores a $16^{\circ} \mathrm{C}$ ) para a retirada da carga térmica excedente (Fig. 1). Um exaustor ao nível do piso foi colocado para assegurar a ventilação de higiene $\left(80 \mathrm{~m}^{3} /\right.$ hora $)$. As 60 porcas primíparas utilizadas (LxLW e LxLWxD) foram uniformizadas por peso, época de parição e raça, e foram alimentadas com $5 \mathrm{~kg} /$ dia de uma dieta formulada à base de milho e soja, com $16 \%$ de PB, 38,5 g/dia de lisina e $16.670 \mathrm{kcal} \mathrm{EM} /$ dia, fornecida em três horários.

Os critérios de correção do bioclima foram baseados nos registros da Estação Agrometeorológica da Embrapa-CNPSA (1985 a 1992), em Concórdia, SC, e nas exigências de conforto da porca em relação a temperatura $\left(16^{\circ} \mathrm{C}\right)$, umidade relativa $(55$ a $75 \%)$ e velocidade do ar $(0,1$ a $0,3 \mathrm{~m} / \mathrm{s})$, sugeridos por Lynch (1977), Veit \& Troutt (1982) e Benedi (1986), respectivamente. A carga térmica incidente por radiação solar na cobertura e nas paredes foi calculada de acordo com o método proposto por Nääs (1989), e a resistência total da cobertura $\left(\mathrm{Rt}=1,0 \mathrm{~W} / \mathrm{m}^{2} /{ }^{\circ} \mathrm{C}\right)$ foi determinada segundo o método proposto por Mascaró \& Mascaró (1988). A produção de calor animal $(671 \mathrm{~W} /$ hora por unidade experimental) foi estimada de acordo com Bianca \& Blaxter (1961) citados por Meyer \& Fossen (1971). A vazão de ventilação necessária para a retirada da carga térmica total foi dimensionada de acordo com Costa (1982) e Mascaró (1986), e o cálculo das superfícies mínimas de abertura e saída para os sistemas naturais foi estimado pela expressão descrita por Nääs (1989).

O registro dos dados experimentais foi realizado a partir do dia do parto até a desmama dos leitões (em torno de 22 dias). As variáveis ambientais foram monitoradas diariamente, medindo-se a temperatura do ar de três em 

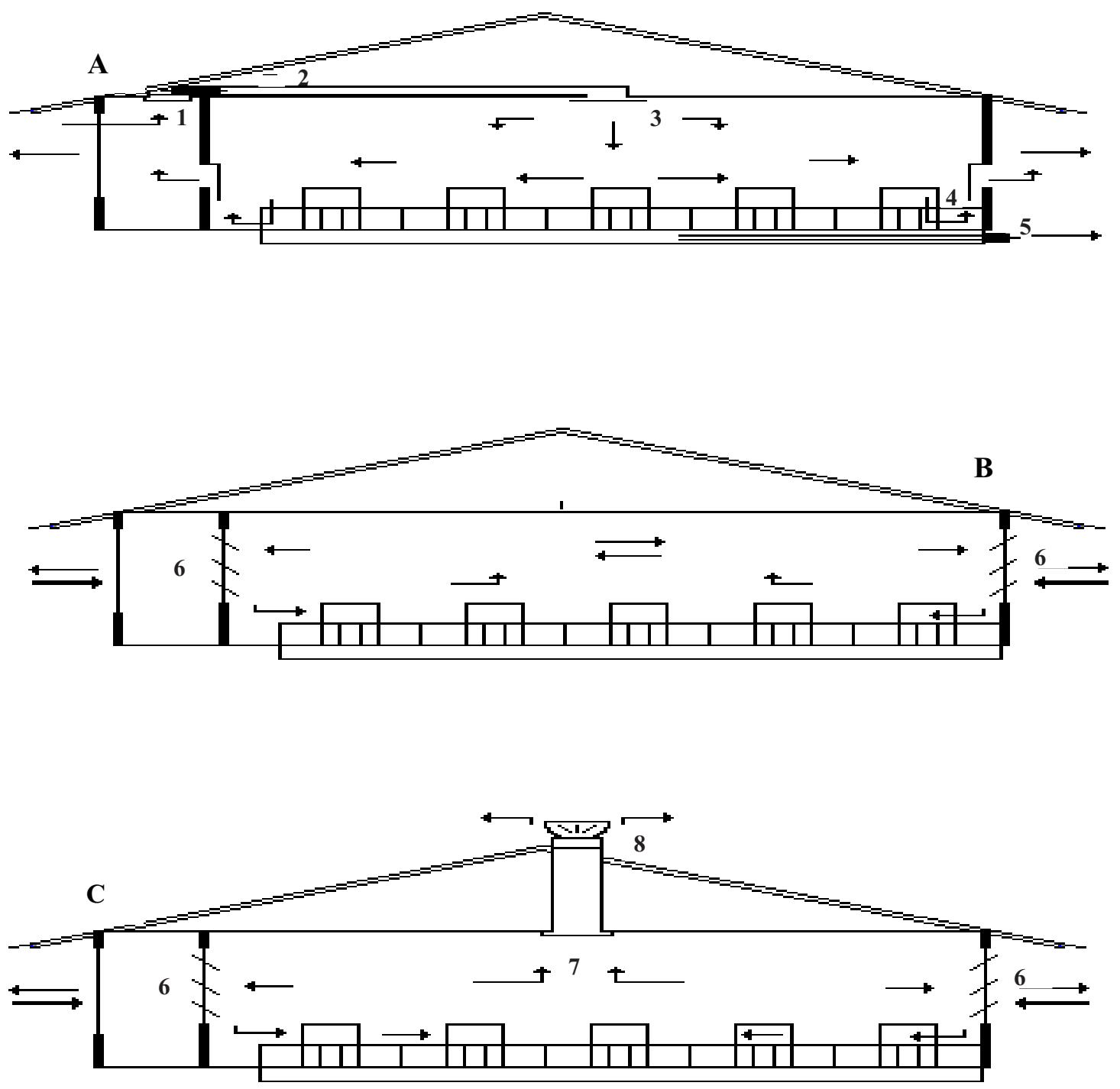

FIG. 1. Esquema geral dos sistemas de tratamento, sendo: A - ventilação mecânica; B - ventilação natural sem exaustor eólico; $C$ - ventilação natural com exaustor eólico; 1 - entrada de ar e ventilador; 2 - tubo de ventilação; 3 - defletor de saída do ar; 4 - abertura de saída do ar; 5 - exaustor de higiene; 6 - janela basculante; 7 - tubo conector; 8 - exaustor eólico. Concórdia, 1991-1992.

três horas, a velocidade do ar de seis em seis horas, a umidade relativa do ar às 9,15 e $21 \mathrm{~h}$, e a concentração de $\mathrm{NH}_{3}$ e $\mathrm{CO}_{2}$, uma vez por semana. A temperatura retal $(9$ e $15 \mathrm{~h})$ e o consumo da porca também foram medidos diariamente, mas a perda de peso e a espessura de toucinho da porca, o consumo e o ganho de peso dos leitões foram anotados do parto à desmama. $\mathrm{O}$ conforto ambiental foi avaliado pelo índice bioclimático (IBC) descrito por Texier et al. (1979), cuja sensação térmica baseia-se no equilíbrio entre a temperatura, a umidade relativa e a velocidade do ar, variando com o peso e com a temperatura corporal do animal; a neutralidade térmica foi alcançada com valores de $\mathrm{IBC}=0$. 
Os dados foram analisados pelo método dos quadrados mínimos, através do procedimento General Linear Models (GLM) do SAS (1985), e as comparações das médias foram feitas pelo teste F. Foram utilizados cinco modelos matemáticos para testar as diferentes variáveis, sendo: (1) quanto à temperatura, umidade relativa e velocidade do ar, ajustados por covariável para as condições vigentes externamente (temperatura, umidade relativa e velocidade do ar externas incidentes no mesmo horário, respectivamente), (2) índice bioclimático, (3) concentração de $\mathrm{NH}_{3}$ e $\mathrm{CO}_{2}$, (4) temperatura retal da porca e seu consumo de ração e (5) perda de peso, espessura do toucinho, intervalo desmama-cio, ganho de peso e consumo de ração de leitões, expressas pelas seguintes equações:

$\mathrm{Y}_{\mathrm{ijkl}}=\mu+\mathrm{T}_{\mathrm{i}}+\mathrm{D}_{\mathrm{j}}+(\mathrm{TD})_{\mathrm{ij}}+\mathrm{H}_{\mathrm{k}}+(\mathrm{TH})_{\mathrm{ik}}+\mathrm{b}\left(\mathrm{X}_{\mathrm{ijk}}-\overline{\mathrm{X}}\right)+\mathrm{e}_{\mathrm{ijk}}$;

$\mathrm{Y}_{\mathrm{ijl}}=\mu+\mathrm{T}_{\mathrm{i}}+\mathrm{D}_{\mathrm{j}}+(\mathrm{TD})_{\mathrm{ij}}+\mathrm{e}_{\mathrm{ijl}}$;

$\mathrm{Y}_{\text {imol }}=\mu+\mathrm{T}_{\mathrm{i}}+\mathrm{P}_{\mathrm{m}}+(\mathrm{TP})_{\mathrm{im}}+\mathrm{S}_{\mathrm{o}}+(\mathrm{TS})_{\mathrm{io}}+\mathrm{e}_{\mathrm{imol}}$;

$\mathrm{Y}_{\mathrm{imnl}}=\mu+\mathrm{T}_{\mathrm{i}}+(\mathrm{TPA})_{\mathrm{mn}(\mathrm{i})}+\mathrm{e}_{\mathrm{imnl}}$;

$\mathrm{Y}_{\mathrm{iml}}=\mu+\mathrm{T}_{\mathrm{i}}+\mathrm{P}_{\mathrm{m}}+\mathrm{e}_{\mathrm{im}}$,

onde:

Y é a variável dependente; $\mu$, a média geral; $T$, o efeito de tratamento; D, o efeito do dia; $\mathrm{P}$, o efeito da repetição no tempo; H, o efeito da hora; $\mathrm{S}$, o efeito da semana de observação; A, o efeito da fêmea; TH e TS, os efeitos das interações entre tratamento e hora e tratamento e semana de observação, respectivamente; TD, o efeito da interação entre tratamento e dia, variável considerada como erro aleatório a - utilizados para testar T nos modelos 1 e 2; TP e TPA, os efeitos das interações entre tratamento e repetição no tempo e tratamento, repetição no tempo e fêmea, considerada como erro aleatório a - são utilizados para testar T nos modelos 3 e 4, respectivamente; b, o coeficiente de regressão linear da variável y para as condições vigentes externamente; $\mathrm{X}$, o valor interno da variável; $\bar{X}$, a média da variável externa; e, o erro aleatório.

\section{RESULTADOS E DISCUSSÃO}

\section{Condicionamento ambiental}

Houve efeito significativo da estação do ano $(\mathrm{P}<0,05)$ sobre os elementos ambientais, decorrentes da variação na magnitude de incidência dos elementos climáticos e do maior controle exercido sobre a ventilação durante o inverno. Observou-se, no verão, um quadro de desconforto térmico em todos os sistemas, caracterizado por temperaturas internas elevadas e deficientes taxas de velocidades do ar, mas confortável no inverno nos sistemas naturais, e moderadamente quente no sistema mecânico (Tabela 1).

$\mathrm{O}$ contraste entre as médias diárias de temperatura interna (Ti) dos tratamentos SVCE, VMEC e SVSE, registram, no verão, valores $43,8,55,4$ e $42,5 \%$ superiores à ótima $\left(16^{\circ} \mathrm{C}\right)$, sugerida por Lynch (1977) para o conforto da porca, e de 2,1, 18,2 e $1,8 \%$ no inverno, respectivamente (Tabela 1 ). O tratamento VMEC apresentou o pior desempenho térmico $(\mathrm{P}<0,05)$ em ambas as épocas, e o SVSE resultou melhor que o $\operatorname{SVCE}(\mathrm{P}<0,05)$ no verão e similares no inverno. As médias diárias do diferencial de temperatura (temperatura interna menos a externa) apresentado pelo $\operatorname{VMEC~}\left(4,69^{\circ} \mathrm{C}\right.$ no verão e $3,31^{\circ} \mathrm{C}$ no inverno) foram superiores aos $2,0^{\circ} \mathrm{C}$ sugeridos por Mascaró \& Mascaró (1988) como o máximo admitido para edifícios climatizados naturalmente, e os do SVCE e SVSE foram inferiores no verão $\left(1,65\right.$ e $\left.1,21^{\circ} \mathrm{C}\right)$ e similares no inverno $\left(2,06\right.$ e $\left.2,10^{\circ} \mathrm{C}\right)$, respectivamente. Considerando-se que todos os tratamentos têm a mesma carga e nível de isolamento térmico, conclui-se, de acordo com as observações de Chosson et al. (1989), que as diferenças existentes dentro de época entre o sistema mecânico e os naturais devem ser atribuídas ao acúmulo do calor gerado internamente em decorrência da menor ventilação observada.

As médias diárias de umidade relativa do ar internas (UR), à exceção da do tratamento VMEC no verão, superaram o valor de $75 \%$ proposto por Veit \& Troutt (1982) quanto à maximização do desempenho de porcas e leitões (Tabela 1). Durante o verão, a UR no VMEC foi inferior à dos sistemas naturais $(\mathrm{P}<0,05)$, reflexo de sua maior capacidade térmica para absorção de vapor d'água (Tabela 1), enquanto a presença do exaustor eólico (SVCE) foi mais eficiente na redução da UR interna do que o sistema sem o dispositivo (SVSE). O comportamento da UR nos sistemas naturais foi considerado irregular durante o inverno, uma vez que, em ambientes subventilados e na ausência de aquecimento, espera-se que, à medida que a temperatura do meio diminua, haja aumento da UR (La Farge et al., 1981). Este aspecto, considerando-se a similaridade entre 
as médias $(78,2$ e $78,2 \%)$ e as amplitudes $(21,2$ e $22,2 \%$ ) diárias da UR externa, observadas no verão e inverno, e a maior amplitude diária de UR nos sistemas naturais (SVCE e SVSE) no verão (5,3 e $6,3 \%$ ) em relação ao inverno (1,7 e 1,8\%), respectivamente, pode ser atribuído à maior perda de água pela respiração animal durante o verão.

As médias diárias de velocidades do ar internas (Vi) foram consideradas críticas para o atendimento das exigências de conforto animal, situando-se, durante o verão, no limite inferior da faixa de 0,1 a $0,3 \mathrm{~m} / \mathrm{s}$ recomendado para a porca em lactação por Benedi (1986), e abaixo deste valor, no inverno (Tabela 1). Não houve diferença entre os tratamentos quanto à velocidade do ar no verão $(\mathrm{P}>0,05)$, mas o VMEC foi inferior aos sistemas naturais no inverno $(\mathrm{P}<0,05)$, como decorrência do mecanismo de controle automático da ventilação, menos acionado nesta época do ano (ocorrência freqüente de temperaturas $<16^{\circ} \mathrm{C}$ ). A utilização do exaustor eólico, ainda que não tenha contribuído para a redução da Ti e aumento da Vi total, teve efetiva participação na redução da UR em ambas as épocas $(\mathrm{P}<0,05)$. A existência de certas similaridades físicas entre os sistemas naturais, a exemplo da área e tipologia de fechamentos, sugere que a velocidade final tenha sido predominantemente por ação do vento. À exceção do tratamento VMEC no inverno, todos os sistemas apresentaram níveis de $\mathrm{NH}_{3}$ e $\mathrm{CO}_{2}$ inferiores aos limites máximos de conforto (10 ppm e $0,03 \%$ ) recomendado por Benedi (1986), respectivamente. Estes resultados, considerando a inexistência de anormalidades sanitárias, demonstram, a exemplo das observações de Pijoan (1994), que a ventilação de higiene foi satisfatória.

O condicionamento ambiental durante o verão, expresso pelo Índice Bioclimático de Conforto (IBC), apresentou um ambiente estressante para os tratamentos SVCE, VMEC e SVSE, mais especialmente no VMEC $(\mathrm{P}<0,001)$, cujos valores ultrapassam em 200,2, 302 e $237 \%$ o limite superior (IBC=2) sugerido para o conforto térmico dos animais por Texier et al. (1979), mas confortável no inverno $(\mathrm{IBC}= \pm 1,0)$ para os sistemas naturais e moderadamente quente no VMEC, respectivamente.

TABELA 1. Temperatura $\left(\mathrm{Ti},{ }^{\circ} \mathrm{C}\right)$, umidade relativa $(\mathrm{UR}, \%)$ e velocidade do $\operatorname{ar}(\mathrm{Vi}, \mathrm{m} / \mathrm{s})$, índice bioclimático de conforto (IBC), níveis de $\mathrm{NH}_{3}(\mathrm{ppm})$ e $\mathrm{CO}_{2}(\%)$, com respectivo erro-padrão da média, e coeficiente de variação da ANOVA (CV). Concórdia, 1991 a 1992'.

\begin{tabular}{|c|c|c|c|c|c|}
\hline \multirow[t]{2}{*}{ Variável $^{2}$} & \multirow[t]{2}{*}{ Estação } & \multicolumn{2}{|r|}{ Sistema $^{3}$} & \multirow[t]{2}{*}{ SVSE } & \multirow[t]{2}{*}{ CV $(\%)$} \\
\hline & & SVCE & VMEC & & \\
\hline \multirow[t]{2}{*}{$\mathrm{Ti}$} & Verão & $23,00 \pm 0,03 b$ & $24,86 \pm 0,03 \mathrm{a}$ & $22,80 \pm 0,03 c$ & 3,4 \\
\hline & Inverno & $16,34 \pm 0,05 b$ & $18,91 \pm 0,05 \mathrm{a}$ & $16,29 \pm 0,03 b$ & 6,5 \\
\hline \multirow[t]{2}{*}{ UR } & Verão & $79,23 \pm 0,56 b$ & $74,47 \pm 0,56 \mathrm{c}$ & $81,36 \pm 0,36 a$ & 11,6 \\
\hline & Inverno & $76,83 \pm 0,41 b$ & $78,06 \pm 0,040 \mathrm{a}$ & $78,82 \pm 0,40 \mathrm{a}$ & 7,3 \\
\hline \multirow[t]{2}{*}{$\mathrm{Vi}$} & Verão & $0,115 \pm 0,003$ & $0,110 \pm 0,003$ & $0,116 \pm 0,003$ & 40,6 \\
\hline & Inverno & $0,100 \pm 0,002 \mathrm{a}$ & $0,065 \pm 0,002 b$ & $0,098 \pm 0,002 \mathrm{a}$ & 41,8 \\
\hline \multirow[t]{2}{*}{ IBC } & Verão & $6,05 \pm 0,16 \mathrm{c}$ & $8,04 \pm 0,16 \mathrm{a}$ & $6,74 \pm 0,16 b$ & 38,4 \\
\hline & Inverno & $0,07 \pm 0,27 b$ & $2,24 \pm 0,27 \mathrm{a}$ & $0,01 \pm 0,27 b$ & 304,8 \\
\hline \multirow[t]{2}{*}{$\mathrm{NH}_{3}$} & Verão & $2,86 \pm 0,61 b$ & $7,51 \pm 0,61 \mathrm{a}$ & $2,21 \pm 0,61 b$ & 46,6 \\
\hline & Inverno & $4,02 \pm 0,56 b$ & $10,46 \pm 0,56 \mathrm{a}$ & $4,18 \pm 0,56 b$ & 27,0 \\
\hline \multirow[t]{2}{*}{$\mathrm{CO}_{2}$} & Verão & $0,030 \pm 0,001$ & $0,033 \pm 0,001$ & $0,030 \pm 0,001$ & 40,6 \\
\hline & Inverno & $0,030 \pm 0,001 b$ & $0,038 \pm 0,001 \mathrm{a}$ & $0,030 \pm 0,001 b$ & 7,0 \\
\hline
\end{tabular}

1 Médias seguidas de mesma letra na linha não diferem estatisticamente entre si pelo teste $\mathrm{F}(\mathrm{P}<0,05)$.

2 As médias de Ti, UR e Vi foram ajustadas por covariável pelas condições externas.

3 SVCE: sistema de ventilação natural com exaustor eólico; VMEC: sistema de ventilação mecânica; SVSE: sistema de ventilação natural sem exaustor eólico. 
Estes resultados demonstram que todos os sistemas estão em regime de subdimensionamento nas condições de verão e, com exceção do VMEC, relativamente adequados no inverno. $\mathrm{O}$ aumento da resistência térmica na cobertura e o maior controle sobre a ventilação possibilitam alcançar maior estabilidade térmica no sistema.

\section{Desempenho animal}

Não houve efeito significativo da estação do ano $(\mathrm{P}>0,05)$ sobre as variáveis de desempenho animal e, à exceção da temperatura retal, o contraste entre as médias de tratamentos dentro de época também não apresentou efeito $(\mathrm{P}>0,05)$ sobre os elementos observados (Tabelas 2 e 3). Aparentemente, as di-

TABELA 2. Temperatura retal $\left({ }^{\circ} \mathrm{C}\right)$ observada, com respectivo erro-padrão da média e coeficiente de variação da ANOVA (CV), de acordo com tratamento e horário. Concórdia, 1991 a 19921.

\begin{tabular}{clcccc}
\hline Horário & Estação & \multicolumn{3}{c}{ Sistema $^{2}$} & \multirow{2}{*}{ CV (\%) } \\
\cline { 3 - 5 } & & \multicolumn{1}{c}{ SVCE } & VMEC & SVSE & \\
\hline \multirow{2}{*}{9} & Verão & $39,01 \pm 0,03$ & $39,05 \pm 0,03$ & $38,96 \pm 0,03$ & 1,3 \\
& Inverno & $38,93 \pm 0,01$ & $39,00 \pm 0,01$ & $38,94 \pm 0,01$ & 0,7 \\
\multirow{2}{*}{15} & Verão & $39,25 \pm 0,03 \mathrm{~b}$ & $39,42 \pm 0,03 \mathrm{a}$ & $39,25 \pm 0,03 \mathrm{~b}$ & 1,5 \\
& Inverno & $39,10 \pm 0,02$ & $39,13 \pm 0,02$ & $39,14 \pm 0,02$ & 0,7 \\
\multirow{2}{*}{ Diária } & Verão & $39,14 \pm 0,02$ & $39,23 \pm 0,02$ & $39,10 \pm 0,02$ & 1,2 \\
& Inverno & $39,02 \pm 0,01$ & $39,07 \pm 0,01$ & $39,04 \pm 0,01$ & 0,6 \\
\hline
\end{tabular}

${ }^{1}$ Médias seguidas de mesma letra na linha não diferem estatisticamente entre si pelo teste $\mathrm{F}(\mathrm{P}<0,05)$.

${ }^{2}$ SVCE: sistema de ventilação natural com exaustor eólico; VMEC: sistema de ventilação mecânica; SVSE: sistema de ventilação natural sem exaustor eólico.

TABELA 3. Consumo de ração (CRP, kg/dia), mobilização de peso (MP, \%) e de espessura de toucinho (ET, \%) do parto à desmama, e intervalo desmama-cio (IDC, dias) das porcas, consumo (CL, kg) e ganho de peso (GPL, kg) dos leitões, com respectivo erro-padrão da média, e coeficiente de variação da ANOVA (CV). Concórdia, 1991 a $1992^{1}$.

\begin{tabular}{|c|c|c|c|c|c|}
\hline \multirow[t]{2}{*}{ Variável $^{2}$} & \multirow[t]{2}{*}{ Estação } & \multicolumn{3}{|c|}{ Sistema $^{3}$} & \multirow[t]{2}{*}{ CV $(\%)$} \\
\hline & & SVCE & VMEC & SVSE & \\
\hline \multirow[t]{2}{*}{ CRP } & Verão & $4,24 \pm 0,06$ & $3,81 \pm 0,07$ & $3,91 \pm 0,06$ & 28,8 \\
\hline & Inverno & $4,61 \pm 1,00$ & $4,57 \pm 1,01$ & $4,73 \pm 0,75$ & 18,8 \\
\hline \multirow[t]{2}{*}{ MP } & Verão & $7,69 \pm 1,13$ & $8,12 \pm 1,13$ & $5,95 \pm 1,13$ & 68,3 \\
\hline & Inverno & $4,69 \pm 1,45$ & $5,88 \pm 1,45$ & $3,57 \pm 1,45$ & 118,9 \\
\hline \multirow[t]{2}{*}{ ET } & Verão & $7,23 \pm 2,75$ & $3,57 \pm 2,75$ & $6,40 \pm 2,75$ & 220,9 \\
\hline & Inverno & $2,13 \pm 2,79$ & $4,30 \pm 2,79$ & $6,46 \pm 2,79$ & 251,9 \\
\hline \multirow[t]{2}{*}{ IDC } & Verão & $13,38 \pm 2,21$ & $13,52 \pm 2,21$ & $13,68 \pm 2,21$ & 70,8 \\
\hline & Inverno & $6,87 \pm 0,95$ & $5,33 \pm 0,95$ & $5,67 \pm 0,95$ & 61,9 \\
\hline \multirow[t]{2}{*}{$\mathrm{CL}$} & Verão & $0,89 \pm 0,14$ & $1,11 \pm 0,14$ & $1,17 \pm 0,14$ & 59,5 \\
\hline & Inverno & $1,65 \pm 0,20$ & $1,15 \pm 0,20$ & $1,17 \pm 0,20$ & 59,6 \\
\hline \multirow[t]{2}{*}{ GLP } & Verão & $34,47 \pm 1,34$ & $32,36 \pm 1,34$ & $31,78 \pm 1,34$ & 17,7 \\
\hline & Inverno & $38,21 \pm 2,01$ & $39,61 \pm 2,01$ & $37,02 \pm 0,95$ & 20,3 \\
\hline
\end{tabular}

Médias não diferentes estatisticamente pelo teste $\mathrm{F}(\mathrm{P}<0,05)$

2 Médias ajustadas para as condições do parto.

3 SVCE: sistema de ventilação natural com exaustor eólico; VMEC: sistema de ventilação mecânica; SVSE: sistema de ventilação natural sem exaustor eólico. 
ferenças existentes no condicionamento térmico entre os tratamentos não foram suficientes para provocar alterações na resposta animal.

A temperatura retal média diária (TR) manteve-se, em todos os tratamentos, dentro do limite de $38,6 \pm 0,8^{\circ} \mathrm{C}$ referido por Carvalho (1982) como faixa normal de porcas em lactação, sugerindo um eficiente ajuste fisiológico para a manutenção da temperatura corporal, especialmente, no verão (Tabela 2). O VMEC apresentou valores de TR mais elevadas do que os naturais $(\mathrm{P}<0,05)$ no período mais quente do dia (15h) durante o verão, o que reflete o seu pior condicionamento térmico.

O consumo de ração das porcas no verão nos tratamentos SVCE, VMEC e SVSE foi inferior aos 4,35 kg/dia observados por O'Grady et al. (1985) na estação quente, representando uma depressão da ordem de 15,2, 23,8 e 21,8\% em relação à quantidade fornecida $(5,0 \mathrm{~kg} / \mathrm{dia})$ e de $0,11,0,13$ e $0,16 \mathrm{~kg} / \mathrm{dia}$ para cada ${ }^{\circ} \mathrm{C}$ de acréscimo na temperatura ambiente em relação a do conforto animal, superando o $0,1 \mathrm{~kg} /$ dia relatado pelos autores, respectivamente. Durante o inverno, à exceção do tratamento SVSE, os consumos também foram inferiores aos 4,69 kg/dia relatados por O'Grady et al. (1985), referentes à estação fria, representando uma redução de 7,8, 8,6 e 5,4\% em relação à quantidade fornecida, mas inferior aos $12 \%$ encontrados pelos autores. Este aspecto reflete o pior condicionamento térmico observado durante o verão.

A ingestão diária de energia das porcas nos tratamentos SVCE, VMEC e SVSE, em relação aos $16.670 \mathrm{kcal} /$ dia de EM fornecidos, reduziu-se para $14.110,12.680$ e 13.012 no verão e $15.342,15.209$ e $15.741 \mathrm{kcal} / \mathrm{dia}$ no inverno, mas ainda superiores às $10.775 \mathrm{kcal} /$ dia referidas por King \& Dunkin (1986) como nível crítico para ocorrência de efeitos deletérios sobre a reprodução, respectivamente. No entanto, a ingestão diária de proteína durante o verão $(678,610$ e 626 g PB/dia) foi inferior aos 700 g PB/dia consideradas por King \& Williams (1984) como o nível de efeito positivo para a indução do estro, mas superior no inverno $(738,731$ e $757 \mathrm{~g} \mathrm{~PB} /$ dia, respectivamente). Portanto, o elevado intervalo desmama-cio, a baixa porcentagem de fêmeas ciclando na primeira semana $(36,8,42,1$ e $21,1 \%$ ) e a alta da terceira semana pós-desmame
$(15,8,21,1$ e $26,3 \%)$ observada durante o verão, em comparação com o desempenho de inverno $(86,7$, 73,3 e $80 \%$ e $6,7,0$ e $0 \%$, respectivamente), são concordantes com as observações de King \& Williams (1984), cuja elevação da ingestão para $700 \mathrm{~g}$ de $\mathrm{PB} / \mathrm{dia}$, isolada ou combinada com acréscimo de energia, aumenta a proporção de fêmeas em estro aos 7-8 dias.

A mobilização da espessura de toucinho não foi proporcional à perda de peso observada (Tabela 3 ). Diversos autores, a exemplo de Whitemore et al. (1980), já haviam alertado de que a perda de peso e de gordura nem sempre são parâmetros concordantes. Johnston et al. (1989) concluíram que, independentemente da ingestão de EM, a porcentagem de gordura corporal tem mínimo controle sobre a manifestação do estro, e portanto, a perda da espessura de toucinho não constitui bom preditor para o desempenho reprodutivo. Estes resultados, de modo geral, sugerem que as alterações corporais têm um efeito discreto sobre o desempenho reprodutivo, a exemplo do observado por Esbenshade et al. (1986), e refletem, fundamentalmente, as condições ambientais.

O consumo de ração e o ganho de peso da leitegada não foram concordantes com a mobilização de peso e gordura corporal e o desempenho reprodutivo das porcas (Tabela 3). Lewis et al. (1978) já haviam observado que esta variação não constitui bom indicador desta eficiência, pois somente $34 \%$ da variação do peso pode ser atribuído à produção de leite da porca.

\section{CONCLUSÕES}

1. Os sistemas de ventilação dimensionados para a retirada da carga térmica incidente (radiação solar, animal e fontes internas de aquecimento) não são suficientes para a remoção do excesso de calor e para a melhoria do conforto térmico durante o verão, mas asseguram a ventilação de higiene e o conforto térmico no inverno.

2. O controle da ventilação em edifícios com isolamento na cobertura $\left(\mathrm{R}=1,0 \mathrm{~W} / \mathrm{m}^{2} /{ }^{\circ} \mathrm{C}\right)$, mediante o emprego de janelas com tipo basculantes e elementos horizontais móveis possibilita alcançar uma relativa estabilização ambiental em ambas as épocas. 
3. O regime de ventilação por ação do vento predomina nos sistemas com ventilação natural; o exaustor eólico não contribui para o aumento da velocidade do ar.

4. O sistema de ventilação mecânica apresenta o pior desempenho térmico, quando é maior a temperatura e menor a velocidade do ar incidente.

5. As diferenças ambientais observadas entre os tratamentos não são suficientes para provocar alterações significativas da resposta animal.

\section{REFERÊNCIAS}

BENEDI, J.M.H. EI ambiente de los alojamientos ganaderos. Madri: Ministério de Agricultura, Pesca y Alimentación, 1986. 28p. (Hojas Divulgadoras, 6/86 HD).

CARVALHO, M.B. Estudo sobre a temperatura retal, freqüência cardíaca e respiratória de suínos (Sus scrofa) criados em Jaboticabal. Belo Horizonte: UFMG, 1982. 52p. Dissertação de Mestrado.

CHOSSON, C.; LAPORTE, E.; GRANIER, R. Estimation journalière de l'hygrométriee des concentration de gaz, poussière e bactéries de l'air de porcherie. Journées de la Recherche Porcine en France, Paris, n.21, p.261-268, 1989.

COSTA, E.C. Arquitetura ecológica: condicionamento térmico natural. São Paulo: Edgar Bücher, 1982. $265 \mathrm{p}$.

ESBENSHADE, K.L.; BRITT, J.H.; ARMSTRONG, J.D.; TOELLE, V.D.; STANISLAW, C.M. Body conditions of sow accross parities and relationship to reproductive performance. Journal of Animal Science, Champaign, v.62, p.1187-1193, 1986.

GRANIER, R.; CHOSSON, C.; RETIF, E.; ROSSEAU, P. Appreciation des circuits d' air et gradients thermiques dans une porcherie pour différents systèmes de ventilation. Journées de la Recherche Porcine en France, Paris, n.21, p.245-252, 1989.

JOHNSTON, L.J.; FOGWELL, R.L.; WELDON, W.C.; AMES, N.K.; ULREY, D.E.; MILLER, E.R. Relationship between body fat and postweaning interval to estrus in primiparous sows. Journal of Animal Science, Champaign, v.67, p.943-950, 1989.

KING, R.H.; DUNKIN, A.C. The effect of nutrition on the reproductive performance of first-litter sow. 4
The relative effect of energy and protein intakes during lactation on the performance of sows and their piglets. Animal Production, Edingburg, v.43, p.319-325, 1986.

KING, R.H.; WILLIAMS, I.H. The effect of nutrition on the reproductive performance of first-litter sow 2. Protein and energy intake during lactation. Animal Production, Edingburg, v.42, p.249-256, 1984.

LA FARGE, B. de; GRANIER, R.; TEXIER, C. Les conditions de ventilation en porcherie d'engraissement: effects du débit et la vitesse de l'air. Journées de la Recherche Porcine en France, Paris, n.13, p.27-38, 1981.

LE DIVIDICH, J.; RINALDO, D. Effect de l'environment thermique sur le performance du porc en croissance. Journées de la Recherche Porcine en France, Paris, n.21, p.219-223, 1989.

LEWIS, A.J.; SPEER, V.C.; HAUGHT, D.C. Relationship between yield and composition of sows milk and weight gain of nursing pigs. Journal of Animal Science, Champaign, v.47, p.634-638, 1978.

LYNCH, P.B. Effect of environmental temperature on lactating sows and their litters. Irish Journal of Agricultural Research, Cork, v.16, p.123-130, 1977.

MASCARÓ, L.M. Energia da edificação: estratégia para minimizar seu consumo. São Paulo: Projetos e Edifícios Associados, 1986. 136p.

MASCARÓ, J.L.; MASCARÓ, L.M. Uso racional de energia em edificações: isolamento térmico. São Paulo: Agência para Aplicação de Energia, 1988. $51 \mathrm{p}$.

MEYER, V.M.; FOSSEN, L.V. Effects of environment on pork production. Ames: Iowa State Univ., Cooperative Extension Service, 1971. 94p.

MORRISON, S.R.; MOUNT, L.E. Adaptation of growing pigs to change in environmental temperature. Animal Production, Edingburg, v.13, p.51-57, 1971.

NÄÄS, I.A. Princípios de conforto térmico na produção animal. São Paulo: Ícone, 1989. 183p.

O'GRADY, J.F.; LYNCH, P.B.; NEY, P.A.K. Voluntary feed intake by lactating sows. Livestock Production Science, Amsterdam, v.12, p.355-365, 1985. 
PIJOAN, C. Fatores medio-ambientales que afetan los problemas respiratorios del cerdo. In: CONGRESSO NACIONAL DE PRODUCCIÓN PORCINA, 8., 1994, Rosário, Argentina. Anales... Rosário: Universidad Nacional de Rosário, 1994. p.4-9.

RIVERO, R. Acondicionamento térmico natural: arquitetura e clima. 2.ed. Porto Alegre: D.C. Luzzatto Ed., 1986. 240p.

SAS INSTITUTE. The GLM procedure. In: SAS INSTITUTE. SAS user's guide: statistics. 5.ed. Cary, NC, 1985. p.435-506.

SOULOUMIAC, D.; ITIER, B. Equilibre thermohydrique d'un bâtiment d'élévage - Conséquences sur la géometrie des ouvrants. Agricultural Building, v.2, p.1411-1414, 1989.

TEXIER, C.; LA FARGE, B. de; GRANIER, R. Influence des variations des principaux facteurs de l'ambiance an porcherie d'engraissment. Journées de la Recherche Porcine en France, Paris, n.11, p.153-164, 1979.

VEIT, H.P.; TROUTT, H.F. Monitoring air quality for livestock respiratory health. Veterinary Medicine and Small Animal Clinician, Lenexa, v.77, p.454-464, 1982.

WHITTEMORE, C.T.; FRANKLIN, M.F.; PEARCE, B.S. Fat changes in breeding sows. Animal Production, Edingburg, v.31, p.183-190, 1980. 